\title{
Assessing the Impact of Morphological Knowledge on Lexical Acquisition and Processing
}

\author{
Baraa A. Rajab (iD \\ English Language Institute, King Abdulaziz University, Jeddah, Saudi Arabia \\ Correspondence should be addressed to Baraa A. Rajab; brajab@kau.edu.sa
}

Received 24 October 2019; Revised 18 March 2020; Accepted 20 May 2020; Published 6 June 2020

Academic Editor: Yi-Shun Wang

Copyright (c) 2020 Baraa A. Rajab. This is an open access article distributed under the Creative Commons Attribution License, which permits unrestricted use, distribution, and reproduction in any medium, provided the original work is properly cited.

\begin{abstract}
The mastery of morphological structure and vocabulary acquisition are significantly associated. However, the association between the abilities of L2 learners to manipulate morphological elements and develop vocabulary size with native Arabic speakers needs to be assessed. This study assesses the impact of morphological knowledge on lexical acquisition and processing among Englishspeaking learners of Arabic. The study focused on gender (masculine/feminine) and the complete number system (singular/dual/ plural) by native English speakers. The error rates and error patterns were analysed carefully to provide insight into the learner's interlanguage grammar through the experiment. The experimental study design was used. The study sample included 40 of L2 Arabic speakers from Arabic language courses at major universities in Northern Virginia and Maryland. These were native English speakers with no exposure to Arabic before their enrolment in the university. The sample was divided into three groups (Group I, individual in the second year of Arabic program, Group II, individual in 3rd or 4th year of the program, and Group III control group, five native speakers of Arabic). Different tasks were presented to the groups, where PsychoPy software was used for task presentation. Audacity Version 2.0 was audio-recorded, transcribed, and coded by the experimenter. The production and comprehension test revealed that morphological problems are prevalent at the advanced proficiency level. It showed the role of animacy for the morphological variability and higher agreement accuracy for human targets. It concluded that morphological variability in L2 Arabic remains a persistent problem even at advanced levels of proficiency, extending to comprehension.
\end{abstract}

\section{Introduction}

Second language (L2) learners experience substantial difficulties in English reading and comprehension. The awareness of the learners concerning the English language issues associated with morphological knowledge and internal structure assists him/her in its texts decoding [1]. However, no such efficient way has been derived for improving the English reading among L2 learners [2]. This requires improving the L2 learner's awareness for the morphological and derivational structure of English. Also, the texts decoding is important to understand the morphemic structure of words.

The school learners limited vocabulary learning is explained based on insufficient vocabulary input from the learner's textbooks [3]. Previous studies depicted that L2 words, along with equivalents of Arabic translation, are better learned compared to the words that lack this feature. L2 learners need to have adequate knowledge regarding the hurdles of L2 vocabulary acquisition because morphological processing is linked to vocabulary learning. The morphological decomposition for lexical access comprises regular inflectional affixes and derivational affixes [4]. However, irregular inflections are likely to be stored as full entries within the mental lexicon [5]. Recent studies on morphological variability in L2 acquisition stated that animacy and semantic gender contribute substantially in the acquisition of agreement. For instance, Alarcón [6] found that L2 learners of Spanish are sensitive to linguistic cues such as semantic gender and animacy to establish correct agreement features.

The complex words of the second language can be interpreted easily and correctly when the students use their understanding concerning the rules of word formation for 
improving their vocabulary. Morphological knowledge awareness and language acquisition is much more than just the identification of constituent morphemes of complex words that are likely to be discriminated either phonologically or semantically [1]. The inflectional morphological variability results from the inability of L2 learners to access the fully specified form due to certain blockage or communication pressure. These types of issues arise prominently during the production phase concerning the variability in the production of L2 learners [7].

Variability in the comprehension of agreement develops among the L2 learners, which suggest applying probing receptive grammar associated tasks. The receptive grammar associated task is responsible for providing additional insight towards the errors that are similar to comprehension and productions tasks assessing the L2 learners. However, the studies manipulating communication pressure or tasks effects are scarce, despite the importance to evaluate theories of L2 morphological variability. For example, Santoro [8] assessed the acquisition of morphological features of gender and number agreement in L2 Italian determiners, adjectives, and pronouns. It showed increased accuracy levels for masculine and singular targets as compared to feminine or plural ones. Majorly, previous studies on morphological variability have only observed the production, which mass the underlying competence of the L2 learners [9].

In the development of sizeable second language, understanding the word formation is integral. Therefore, L2 learners need to gain insights regarding the morphological processing of target language because it increases their vocabulary skill [4]. Earlier, significant number of studies assessed the morphological knowledge concerning L2 acquisition [10]. Also, significant association exists between morphological structure and vocabulary acquisition mastery [4]. However, studies assessing the association between abilities of L2 learners to manipulate morphological elements and develop vocabulary size with native Arabic speakers are scarce. Therefore, the present study aims to assess the impact of morphological knowledge on lexical acquisition and processing among L2 learners. Concerning the present study, tapping into the morphological processing via lexical decomposition is considered adequate. The research questions addressed in this study are as follows:

(1) What are the error patterns of agreement morphology in terms of gender (masculine and feminine) and number (singular and dual)?

(2) Is morphological variability in the production task similar to morphological variability in the comprehension task?

\section{Theoretical Framework}

The study used the theoretical framework of the Missing Surface Inflection Hypothesis (MSIH) [11]. It proposes that L2 abstract morphosyntactic knowledge does not represent any associated functional projections. Simply, it reflects that the lack of grammatical knowledge is not related to a lack of language production [12]. This inconsistent use of the inflectional morphology is presented in various studies such as Albirini et al. [13], which showed Egyptian heritage speakers overuse of SVO words at places where VSO is preferred. It may be due to the absence of the English (transfer words, i.e., and/or).

Likewise, Muroya [14] shows this discrepancy among the Japanese L2 learners where the use of -s inflection is found for the subject-verb agreement production task. Several other studies have also shown that the "default" and "unmarked" terms are overgeneralized by the heritage speakers linked to the number, gender, and word order $[13,15]$. Ahn and Herschensohn [16] study on the Korean L2 learners showed that written and spoken tests among the learners were different. Albirini and Benmamoun [17] also showed that the L2 learners and heritage speakers face similar problems in the nonconcatenative plural morphology such as plural with defective roots or with geminated. In the same context, the study intends to evaluate the impact of morphological knowledge on lexical acquisition and processing among L2 learners.

\section{Materials and Methods}

3.1. Study Design. An experimental study design is used to address the Arabic agreement in the nominal domain consisting of a head noun and an attributive adjective. The error rates and error patterns in the two tasks are carefully analysed to provide insight into the learner's interlanguage grammar. The source of morphological variability in L2 learners is not simply a performance issue if the error patterns in both tasks are qualitatively similar.

3.2. Study Sample. The study has recruited 40 speakers of L2 Arabic from Arabic language courses at major universities in Northern Virginia and Maryland. The participants were native English speakers with no exposure to Arabic before their enrolment in the university. The participants were grouped in two as per their placement in the Arabic program and their length of exposure to Arabic.

(i) Group I: individuals in their 2nd year of the Arabic program and had received between 135 and 180 hours of formal instruction in Arabic

(ii) Group II: individuals in their $3^{\text {rd }}$ or $4^{\text {th }}$ year of the program and had received more than 225 hours of instruction

(iii) Control group: five native speakers of Arabic, who were teachers of Arabic at the university level

3.3. Data Collection. The elicited production tasks, including two vocabulary tests, were used as a data collection tool. Each set included 48 coloured pictures to elicit the production of a noun plus an adjective. Table 1 has provided sample complete list of test items, while Table 2 has provided a list of adjectives, which the pictures were meant to elicit. These adjectives agree with the head noun in gender and number as shown. 
TABLE 1: Sample elicited production task items by gender and number from vocabulary set 1 .

\begin{tabular}{|c|c|c|c|c|c|c|}
\hline & \multicolumn{2}{|c|}{ Singular } & \multicolumn{2}{|c|}{ Dual } & \multicolumn{2}{|c|}{ Plural } \\
\hline & Masc & Fem & Masc & Fem & Masc & Fem \\
\hline \multirow{2}{*}{ Human } & $\begin{array}{l}\text { Mohandis } \\
\text { "engineer" }\end{array}$ & $\begin{array}{l}\text { Raqisa } \\
\text { "dancer" }\end{array}$ & $\begin{array}{l}\text { Mohandisan "2 } \\
\text { engineers" }\end{array}$ & $\begin{array}{l}\text { Raqisatan "2 } \\
\text { dancers" }\end{array}$ & $\begin{array}{l}\text { Mohandisuun } \\
\text { "engineers" }\end{array}$ & $\begin{array}{l}\text { Raqisaat } \\
\text { "dancers" }\end{array}$ \\
\hline & Riyady "athlete" & $\begin{array}{l}\text { t'aaliba } \\
\text { "student" }\end{array}$ & Riyadyan "2 athletes" & $\begin{array}{l}\text { t aalibatan "2 }^{\star} \text { students" } \\
\text { sten }\end{array}$ & Riyadyuun "athletes" & $\begin{array}{l}\text { taalibaat } \\
\text { "students" }\end{array}$ \\
\hline Nonhuman & $\begin{array}{l}\text { Qalam "pen" } \\
\text { Kalb "dog" }\end{array}$ & $\begin{array}{l}\text { Sayyara "car" } \\
\text { Qitta "cat" }\end{array}$ & $\begin{array}{l}\text { Qalaman "2 pens" } \\
\text { Kalban "2 dogs" }\end{array}$ & $\begin{array}{l}\text { Sayyaratan "2 cars" } \\
\text { Qittatan "2 cats" }\end{array}$ & $\begin{array}{l}\text { Aqlam "pens" } \\
\text { Kilab "dogs" }\end{array}$ & $\begin{array}{l}\text { Sayyaraat "cars" } \\
\text { Qittaat "cats" }\end{array}$ \\
\hline
\end{tabular}

TABLE 2: Sample adjectives by gender and number.

\begin{tabular}{|c|c|c|}
\hline & Masculine & Feminine \\
\hline Singular & $\begin{array}{c}\text { Sayeer "small" } \\
\text { Kabeer "big" } \\
\text { Jameel "nice/handsome" }\end{array}$ & $\begin{array}{c}\text { Sayeera "small" } \\
\text { Kabeera "big" } \\
\text { Jameela "nice/beautiful" }\end{array}$ \\
\hline Dual & $\begin{array}{c}\text { Sayeeran "small" } \\
\text { Kabeeran "big" } \\
\text { Jameelan "nice/handsome" }\end{array}$ & $\begin{array}{l}\text { Sayeeratan "small" } \\
\text { Kabeeratan "big" } \\
\text { Jameelatan "nice/ } \\
\text { beautiful" }\end{array}$ \\
\hline Plural & $\begin{array}{l}\text { Sayeeruun "small" } \\
\text { Kabeeruun "big" } \\
\text { Jameeluun "nice/ } \\
\text { handsome" }\end{array}$ & $\begin{array}{l}\text { Sayeeraat "small" } \\
\text { Kabeeraat "big" } \\
\text { Jameelaat "nice/ } \\
\text { handsome" }\end{array}$ \\
\hline
\end{tabular}

The comprehension test constitutes of 48 target sentences comprising noun and adjective phrases. The genderbalanced noun phrases (masculine, feminine) were used, following the number (singular, plural, dual) and with equal target items, i.e., human and nonhuman (evenly split between animate and inanimate). A picture was shown for each phrase, which included two distractors. For the human target test, the pictures displayed were either with incorrect gender or incorrect number, whereas no manipulation was made for the nonhuman targets. The test also comprised filler items presented as 20 additional verb phrases sentences. Figure 1 presents the sample picture used in the comprehension test, which required the participants to select the picture with a farmer.

Prior to administrating the tasks, the participants were first asked a set of demographic questions. Half the participants completed production first and the other half comprehension first to ensure that the type of task (comprehension or production) and lexical items did not affect the participants' performance. Moreover, the participants were divided equally between vocabulary sets 1 and 2 to ensure that the set of lexicon items did not influence the results.

3.4. Data Analysis. The task was presented using PsychoPy software, with pictures presented in a randomized order for each participant. Each session with each participant was audio-recorded using Audacity Version 2.0 (2013), transcribed, and coded by the experimenter.

\section{Results}

The study has analysed accuracy rates with a series of mixed effects and logistic regression models. The analysis was conducted using $\mathrm{R}$ and the lme4 package [18].
4.1. Production Results. 1920 tokens of $N+$ Adj phrases were yielded in the production task, among which 1494 tokens were included in the analysis for both gender and number agreement.

4.2. Gender Analysis. The mean accuracy rates for each group on adjectival gender inflection are illustrated in Figure 2. The figure showed an increase in the overall rate for the HP (High Proficiency) group compared to the LP (Low Proficiency) for both genders. Numerically higher accuracy rates for masculine target adjectives were found across both the groups as compared to feminine. Significant effect of proficiency $\left(\chi^{2}(5)=8.79, p=0.003\right)$ was confirmed through likelihood ratio tests. However, there was no significant effect of gender $\left(\chi^{2}(6)=1.65, p=0.19\right)$ and no significant effect of the interaction between proficiency and gender $\left(\chi^{2}(7)=0.24, p=0.62\right)$.

4.3. Number Analysis. The mean accuracy rates for each group on adjectival number inflection are presented in Figure 3. As compared to dual and plural, the accuracy rates were significantly higher for singular target adjectives across both groups. An overall significant effect for adjective number $\left(\chi^{2}(6)=76.21, p<0.001\right)$ and significant interaction between proficiency and adjective number $\left(\chi^{2}(8)=8.33\right.$, $p=0.015)$ was observed when the effect of proficiency and target adjective number was assessed. The results depicted weak significance for both proficiency groups, plural and dual, as compared to singular (LP: pl-sg $\beta=-1.96 \pm 0.39$, $p<0.001$; dual-sg $\beta=-3.02 \pm 0.37, p<0.001$ and for HP: $\beta=-2.63 \pm 0.33, p<0.001$, pl-sg $\beta=-2.62 \pm 0.29, p<0.001)$. The LP group has particular difficulty with dual agreement because dual was significantly worse than plural for the LP group $(\beta=-1.07 \pm 0.38, p=0.01)$ but not for the HP group $(\beta=0.01 \pm 0.26, p=0.99)$.

The results depicted that LP learners face trouble with nonhuman nouns; however, the accuracy rates on feminine singular adjectival agreement were lower as compared to masculine singular (Figure 4). Close analysis of this aspect revealed that low accuracy rates were driven by masculine plural nonhuman target nouns (48\%) and feminine nonhuman plural target nouns (53\%). Figure 3 has shown significant main effect of animacy $(\beta=-0.73 \pm 0.13$, $p<0.0001)$ and significant interaction of animacy and target noun gender $(\beta=-0.28 \pm 0.13, p=0.03)$. Moreover, there was significant three-way interaction of animacy, target 


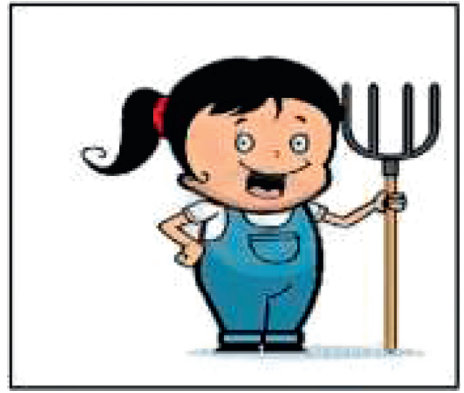

(a)

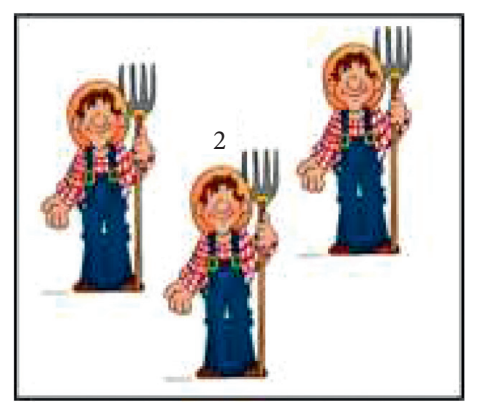

(b)

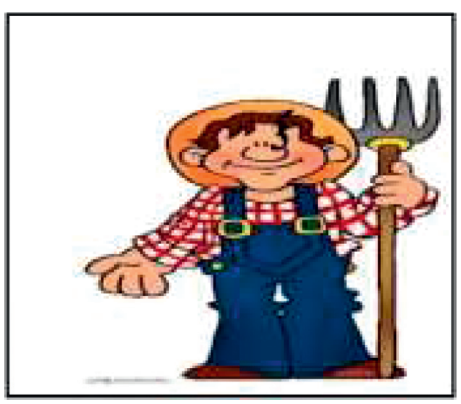

(c)

Figure 1: Comprehension task sample test items.

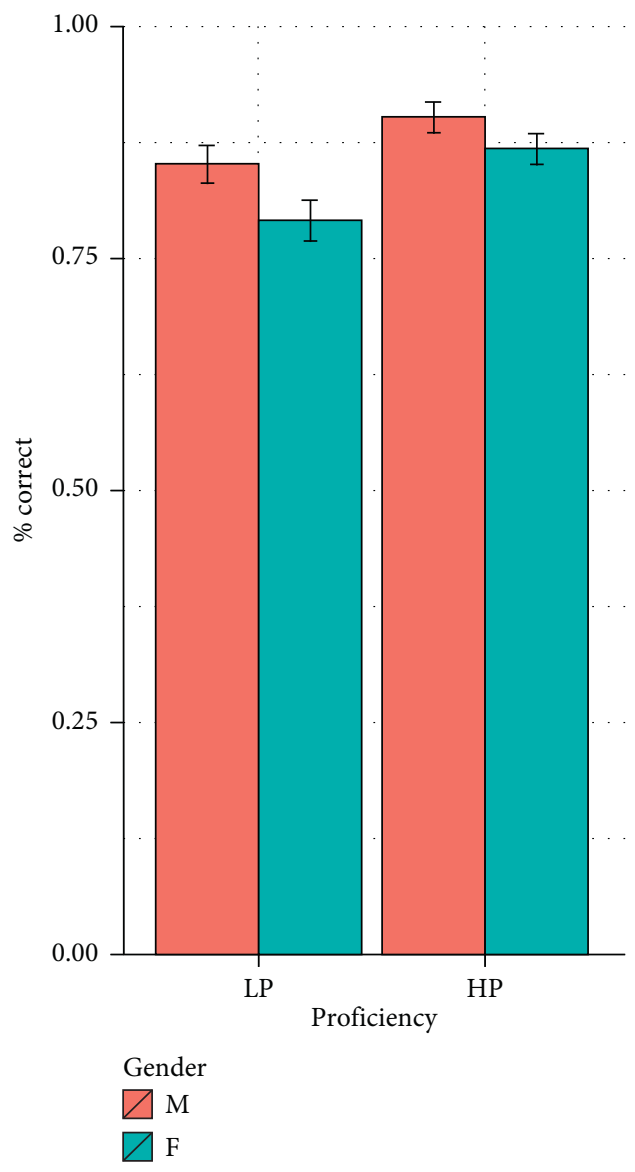

Figure 2: Mean \% accuracy of adjective inflection on the production task, by proficiency and gender across proficiency groups.

noun gender, and target noun number $(\beta=-0.29 \pm 0.13$, $p=0.02)$.

Figure 5 has shown the assessment of the effect of target noun number, target noun gender, and animacy on accuracy in the LP group. A significant main effect of animacy $(\beta=-0.73 \pm 0.21, p=0.0005)$ and a significant main effect of target noun number $(\beta=-0.47 \pm 0.21, p=0.02)$ was confirmed through the likelihood ratio tests. These tests also depicted significant interaction of target noun number and target noun gender $(\beta=-0.71 \pm 0.20, p=0.0006)$ and a

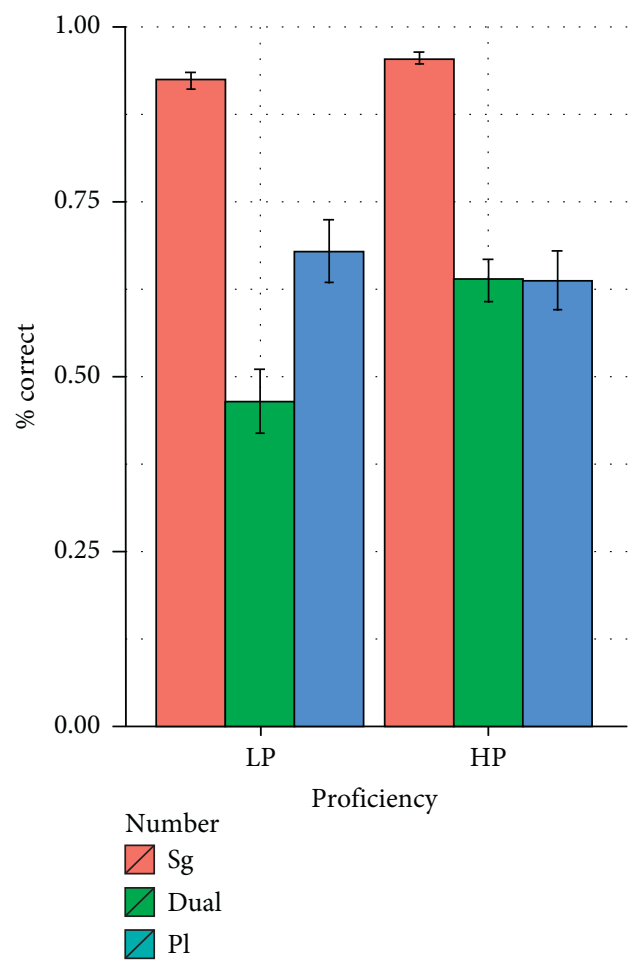

Figure 3: Mean \% accuracy of adjective inflection on the production task, by proficiency and number across proficiency groups.

significant interaction of animacy and target noun gender $(\beta=-0.41 \pm 0.20, p=0.04)$. These results show the lower accuracy rates on nonhuman noun targets and plural targets.

4.4. Error Analysis. These results focused on errors involving incorrect gender and number specification when the target noun itself is produced with the correct gender and number, and the target noun is nonhuman masculine plural. The results from both the groups showed that participants committed more of the number of errors ( $\mathrm{LP}=52 \%$, $\mathrm{HP}=46 \%)$ as compared to gender errors ( $\mathrm{LP}=29 \%$, $\mathrm{HP}=17 \%)$. The gender errors are, for the most part, driven by the LP group and tend to occur with plural targets. The adjectival agreement system is illustrated in Table 3, 


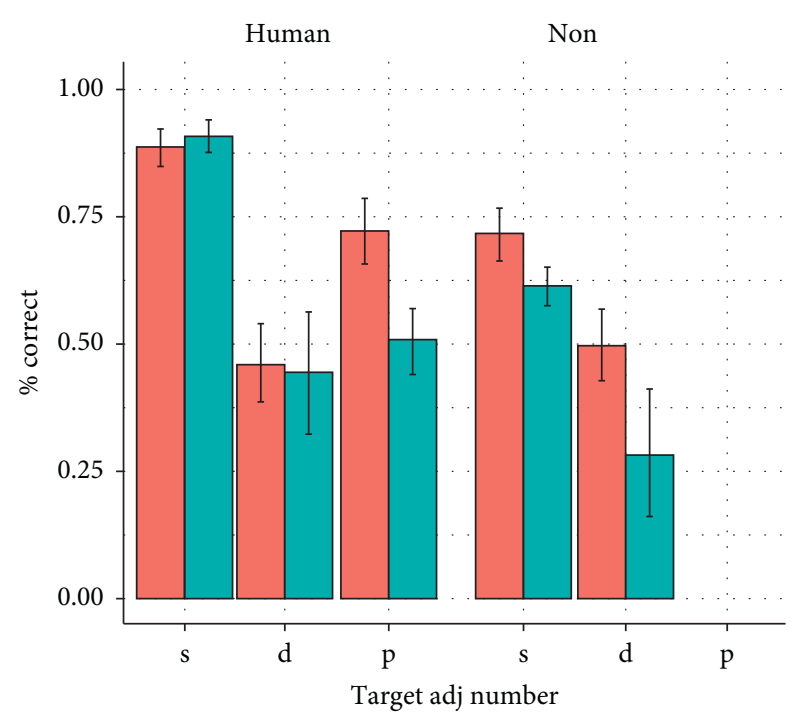

Target adj gender

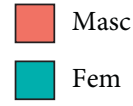

Figure 4: Mean \% correct for singular, dual and plural adjective inflection for LP.

indicating the required adjective form given a noun with the features indicated by column and row headers.

The adjective number and gender response for both of the proficiency groups, in the case, when target noun is dual masculine and feminine (Tables 4 and 5). The tables clarify that the proficiency groups tend to provide singular adjectives when dual adjectives are required, and they rarely use plural adjectives in place of duals. There are a fair number of errors involving the production of the feminine singular when the target is masculine. A closer analysis of this aspect shows errors are almost exclusively made on nonhuman nouns (13\% of errors for nonhuman as compared to $6 \%$ for human nouns).

\subsection{Comprehension Results}

4.5.1. Gender Analysis. The comprehension test revealed that noun gender and proficiency substantially impact proficiency $\left(\chi^{2}(4)=6.16, p=0.01\right)$, the insignificant impact of gender $\left(\chi^{2}(5)=0.071, p=0.79\right)$, and the link between gender and proficiency $\left(\chi^{2}(6)=4.046, p=0.044\right)$. Figure 6 shows that LP accuracy level was higher from HP group in terms of feminine targets, while overall, it was higher for HP group.

4.5.2. Number Analysis. The number analysis revealed that proficiency and number have a substantial impact on the noun inflection accuracy rate, that is, $\chi^{2}(4)=26.44$, $p<0.0001$ and $\chi^{2}(6)=13.565, p=0.001$, receptively. It also reveals no impact on the interaction between proficiency and number $\chi^{2}(8)=0.944, p=0.62$. Both groups had the worst accuracy level for plural noun as compared to singular (such

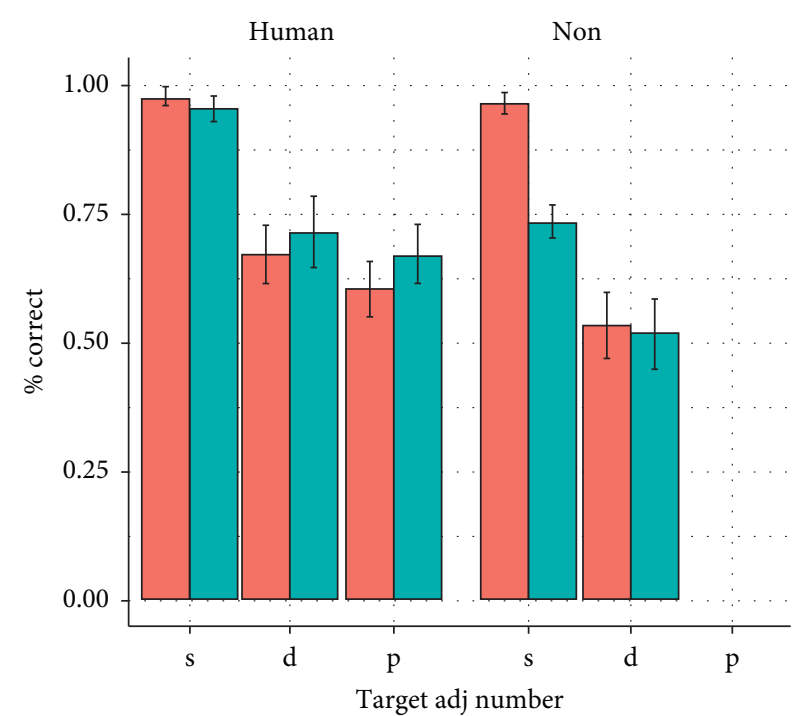

Target adj gender

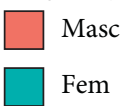

FIgURE 5: Mean \% correct for singular, dual, and plural adjective inflection for HP.

TABLE 3: Schematic illustration of adjectival agreement paradigm in modern standard Arabic.

\begin{tabular}{lcccc}
\hline & \multicolumn{2}{c}{ Masculine } & \multicolumn{2}{c}{ Feminine } \\
& Human & Nonhuman & Human & Nonhuman \\
\hline Singular & M.Sg. & M.Sg. & F.Sg & F.Sg \\
Dual & M.Dual & M.Dual & F.Dual & F.Dual \\
Plural & M.Pl & F.Sg & F.Pl. & F.Sg \\
\hline
\end{tabular}

TABle 4: Adjective number and gender responses (target noun is masculine).

\begin{tabular}{lcc}
\hline & Masculine (\%) & Feminine (\%) \\
\hline Singular & 29 (default) & 14 \\
Dual & 55 (correct) & 0 \\
Plural & 1 & $<1$ \\
\hline
\end{tabular}

TABLE 5: Adjective number and gender responses (target noun is feminine).

\begin{tabular}{lcc}
\hline & Masculine (\%) & Feminine (\%) \\
\hline Singular & 0 (default both) & 33 (default number) \\
Dual & 8 (default gender) & 55 (correct) \\
Plural & 0 & 5 \\
\hline
\end{tabular}

as LP: pl-sg $\beta=-1.13 \pm 0.35, \quad p=0.002$ and HP: $\beta=-1.135 \pm 0.34, p=0.003$ ). This may be due to the featural inconsistency between the nonhuman nouns and adjective (Figure 7).

The results showed that the LP group has low accuracy for the nonhuman targets as compared to the human targets, 


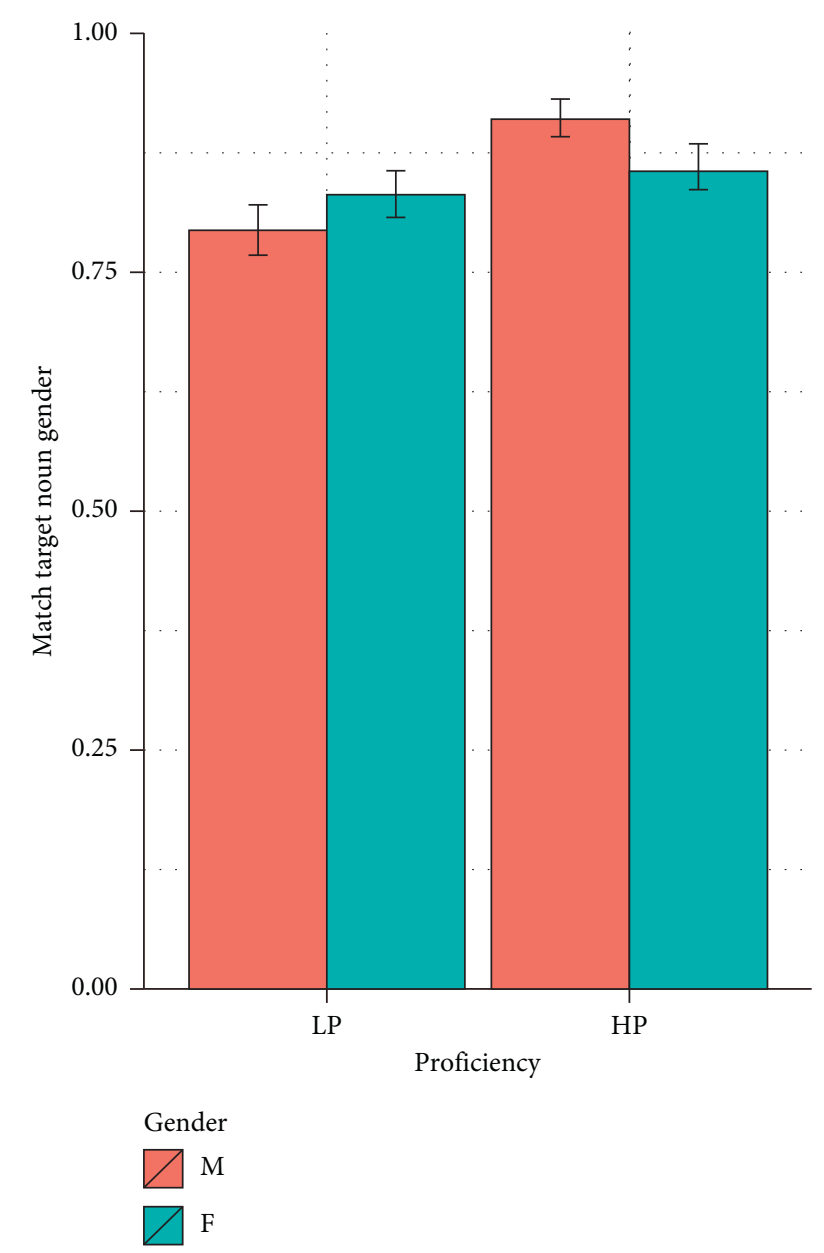

Figure 6: Correct mean \% of the comprehension task by proficiency and gender.

where they primarily lack the competence for worst nonhuman plural. The likelihood results showed that there is a substantial effect of animacy followed by a dual number, plural, and the interaction between plural number and animacy, $\quad \beta=-0.84 \pm 0.106, \quad p<0.001, \quad \beta=0.49 \pm 0.155$, $p=0.001, \beta=-0.48 \pm 0.14, p<0.001$ and $\beta=-0.31 \pm 0.14$, $p=0.03$, respectively (Figure 8 ).

Figure 9 shows the impact on HP group, highlighting the substantial impact of animacy, dual number, and plural number, i.e., $\beta=-0.71 \pm 0.13, p<0.0001, \beta=0.66 \pm 0.21$, $p=0.001, \beta=-0.71 \pm 0.16, p<0.0001$, respectively, whereas it showed no impact on the interaction between animacy and target noun number. The findings reveal that nonhuman plural nouns serve as a problematic area in the comprehension task as well.

4.5.3. Error Analysis. Table 6 illustrates the results for the choice of the picture with a singular and plural noun. It showed that participants were more inclined to choose plural distractor image rather than single. This is different from the results of production task, which may account for the inadequate understanding of the dual suffix, which leads

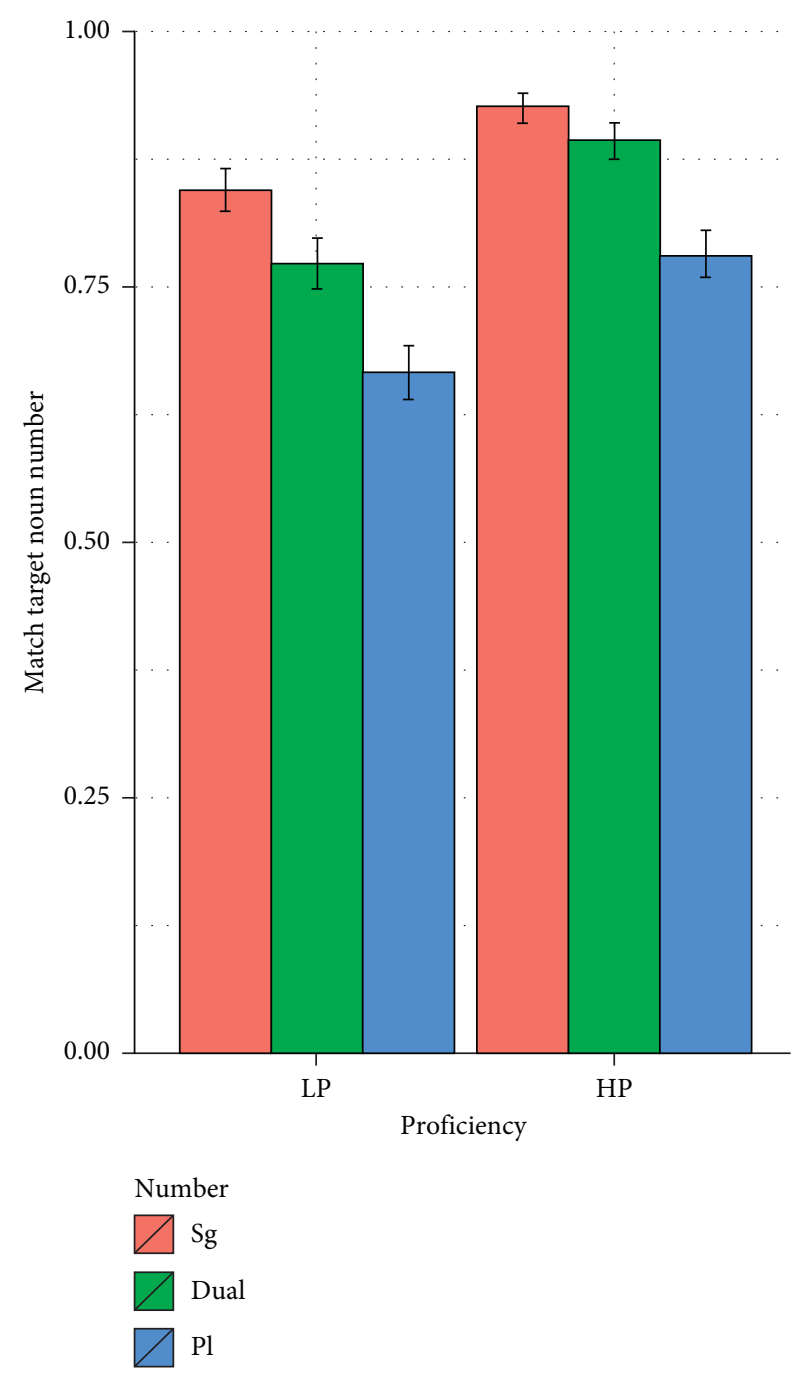

Figure 7: Correct mean \% for noun inflection on the comprehension task by proficiency and number.

them to change the suffix to plural, as in Arabic, the singular form is bare.

The use of singular nouns instead of plural was found for both HP and LP groups (Tables 7 and 8). It shows that the nonhuman targets lead to the low accuracy of the groups, which leads to selection of singular number as compared to the plural nonhuman targets.

\section{Discussion}

The results showed the production of a similar pattern through the comprehension task, as the production task. The L2 learners across both proficiency groups were able to identify gender better than number agreement within NPs, which persisted in both human and nonhuman nouns. L2 learners' accuracy rates were numerically higher for masculine than feminine agreement with no statistical significance. Feminine gender emerges in masculine contexts when analysing errors in the feature gender. These contexts were also human masculine singular target nouns to control for 


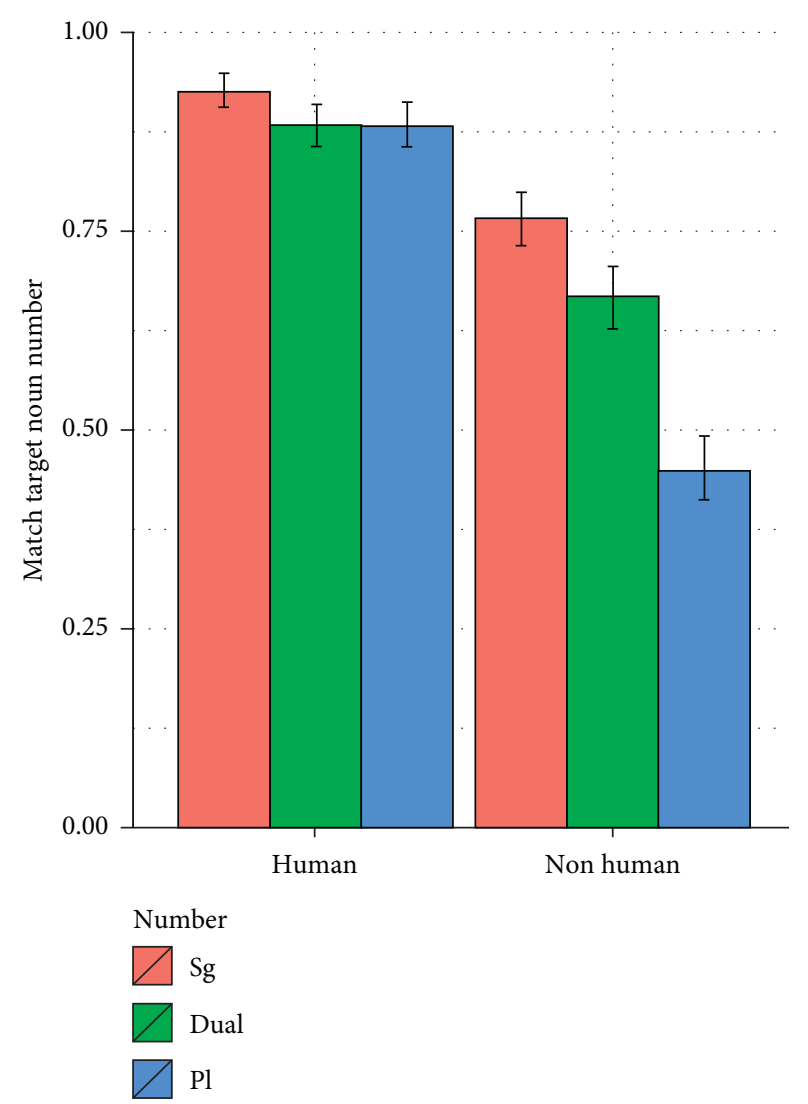

Figure 8: Correct mean \% on noun inflection by number and animacy for LP.

animacy effects. These results endorse the previous findings, such as those of Albina et al. [19] and Albrini et al. [17], which showed that Arabic speakers do not fully acquire the Arabic number system and usually adopt feminine plural forms as their default form. Likewise, Alkohlani [20] on the Arabic L2 study found that feminine gender is generally overgeneralized by L2 learners for both masculine and feminine nouns. Lastly, the agreement paradigm itself depicts that in gender neutralization, feminine is used instead of masculine.

Dual and plural number were problematic for learners, with accuracy on the plural number being particularly low for the LP group as opposed to the production task, while the singular number was unproblematic across proficiency levels. The poor performance on plural across both proficiency groups stems from a particular set of nouns neutralizes the agreement paradigm similar to what occurs at production task. The plural accuracy rates for singular and plural human target nouns were consistently high when the results were broken down by gender, number, and animacy. They were lower for nonhuman masculine plural nouns, which suggested that L2 learners do not struggle with plural in general, rather they agree to the pattern of the nonhuman masculine plural nouns. In regards to dual, L2 learners were more successful in the comprehension task as compared to the production task. This greater accuracy tends to support the predictions of the MSIH, which reducing communication pressure that, in turn, reduces variability [11].

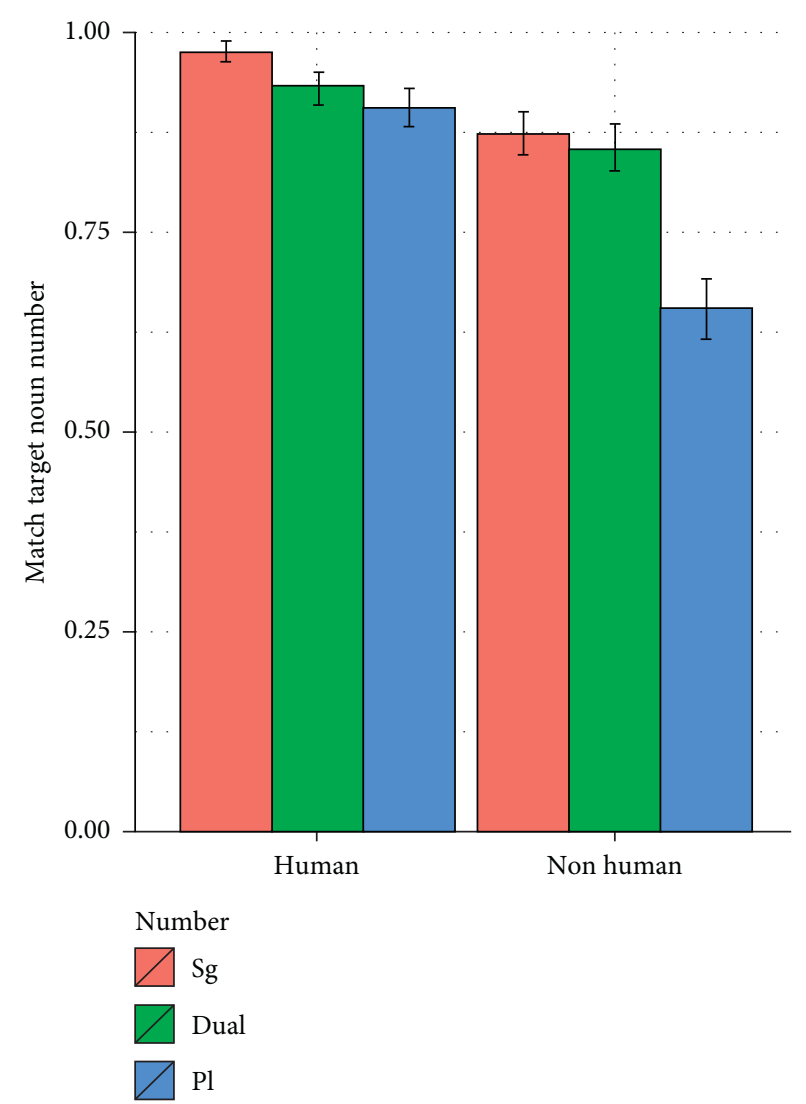

FIgURE 9: Correct mean \% on noun inflection by number and animacy for HP.

TABLE 6: Number errors for dual nouns by proficiency.

\begin{tabular}{lcc}
\hline & LP (\%) & HP (\%) \\
\hline Singular & 23 & 18 \\
Plural & 77 & 82 \\
\hline
\end{tabular}

TABle 7: Number errors for plural nouns by proficiency.

\begin{tabular}{lcc}
\hline & LP (\%) & HP (\%) \\
\hline Singular & 74 & 76 \\
Plural & 26 & 24 \\
\hline
\end{tabular}

TABLE 8: Number substitution for nonhuman plural nouns by proficiency.

\begin{tabular}{lcc}
\hline & LP (\%) & HP (\%) \\
\hline Singular & 80 & 78 \\
Dual & 20 & 22 \\
\hline
\end{tabular}

In the both tasks, the variability in gender agreement decreases with increasing proficiency; however, it remains present even at the advanced level. On the contrary, accuracy rates on number features are significantly lower than gender for the L2 speakers. The dual and plural numbers were problematic for learners, while the singular number is unproblematic across all proficiency levels. Previous studies showed higher accuracy rates for gender and poorer 
accuracy rates for number runs [9, 21-26]. However, poor accuracy rates in plural are largely attributed to the nonhuman masculine subclass of nouns that points towards the importance of studying cases of neutralization in the agreement paradigm. In addition to gender and number, results across both tasks indicate an overall effect of animacy.

In the present study, the results of both tasks confirm that L2 learners are sensitive to animacy when acquiring gender and number features, specifically agreement features between a head noun and attributive adjectives. Alkohlani [20] stated that the absence of morphological and semantic gender cues on the noun causes ambiguity for these L2 learners. In these cases, learners tend to overgeneralize the feminine gender to both masculine and feminine nouns. The present study supports the results of Alarcón [6], who stated that L2 speakers are influenced by linguistic cues while acquiring grammatical gender. Alarcón [6] found that L2 speakers use these linguistic cues for establishing correct gender agreement, and Spanish L2 speakers are sensitive not just to linguistic cues, but also to overtness. These findings clarified the reason why L2 speakers in this experiment have low accuracy rates, especially when the target noun is nonhuman masculine plural. One reason is that these nouns are not derived concatenative, attaching a plural morpheme overtly to the stem. The lack of transparent markings on nonhuman plural nouns leads to less reinforcement of agreement features. It seems that factors play an important role in acquiring agreement features between nonhuman plural nouns and the attributive adjective such as absence of semantic gender on nonhuman plural nouns and absence of overt plural markings on the nouns.

\section{Conclusions}

The study has shown that morphological variability in L2 Arabic remains a persistent problem even at advanced levels of proficiency, extending to comprehension. Moreover, gender agreement acquisition across both tasks was less problematic. Learners had trouble with dual forms, particular at lower proficiency levels, though this was attenuated in comprehension (supporting the MSIH). Moreover, the errors involving the use of feminine in masculine contexts occurred in both tasks, but it was not a general pattern. The effect of animacy (human vs. nonhuman) was present in both tasks resulting in the production and interpretation of correct gender and number. Neutralized agreement likewise presented a persistent and substantial problem for learners across both tasks. However, future studies need to analyse this pattern occurring elsewhere, such as DO clitics. This would strengthen any conclusions regarding similarities and differences in morphological variability across comprehension and production.

\section{Data Availability}

The datasets used and analysed during the current study are available from the corresponding author on reasonable request.

\section{Conflicts of Interest}

The author declares that there are no conflicts of interest regarding the publication of this paper.

\section{Acknowledgments}

The author is very thankful to all the associated personnel in any reference that contributed to/in this research.

\section{References}

[1] L. Yager, N. Hellmold, H.-A. Joo et al., "New structural patterns in moribund grammar: case marking in heritage German," Frontiers in Psychology, vol. 6, 2015.

[2] M. J. Kieffer, N. K. Lesaux, and K. Lesaux, "The role of derivational morphology in the reading comprehension of Spanish-speaking English language learners," Reading and Writing, vol. 21, no. 8, pp. 783-804, 2008.

[3] A. Alsaif and J. Milton, "Vocabulary input from school textbooks as a potential contributor to the small vocabulary uptake gained by English as a foreign language learners in Saudi Arabia," The Language Learning Journal, vol. 40, no. 1, pp. 21-33, 2012.

[4] A. M. Masrai, "The influence of morphological knowledge on lexical processing and acquisition: the case of Arab EFL learners," Ampersand, vol. 3, pp. 52-60, 2016.

[5] M. T. Ullman, "Contributions of memory circuits to language: the declarative/procedural model," Cognition, vol. 92, no. 1-2, pp. 231-270, 2004.

[6] I. V. Alarcón, "Gender assignment and agreement in L2 Spanish: the effects of morphological marking, animacy, and gender," Studies in Hispanic and Lusophone Linguistics, vol. 3, no. 2, pp. 267-299, 2010.

[7] M. T. Alhawary, "L2 acquisition of Arabic morphosyntactic features," Perspectives on Arabic Linguistics, vol. 17, no. 18, pp. 273-312, 2005.

[8] M. Santoro, "Morphological Variability in interlanguage grammars: new evidence from the acquisition of gender and number in Italian determiner phrases and direct object pronouns," The Canadian Journal of Applied Linguistics, vol. 15, no. 1, pp. 167-189, 2012.

[9] C. McCarthy, "Morphological variability in the comprehension of agreement: an argument for representation over computation," Second Language Research, vol. 24, no. 4, pp. 459-486, 2008.

[10] C. M. CHANG, R. K. Wagner, A. Muse, B. W. Y. Chow, and H. U. A. Shu, "The role of morphological awareness in children's vocabulary acquisition in English," Applied Psycholinguistics, vol. 26, no. 3, pp. 415-435, 2005.

[11] P. Prévost and L. White, "Missing surface inflection or impairment in second language acquisition? evidence from tense and agreement," Second Language Research,vol. 16, no. 2, pp. 103-133, 2005.

[12] F. Khorvash and A. R. Lotfi, "Grammatical proficiency and access to extended projections in Iranian learners of English as a second language," Cogent Education, vol. 6, no. 1, p. 1592275, 2019.

[13] A. Albirini, E. Benmamoun, and E. Saadah, "Grammatical features of Egyptian and Palestinian Arabic heritage speakers' oral production," Studies in Second Language Acquisition, vol. 33, no. 2, pp. 273-303, 2011.

[14] A. Muroya, "Interpreting morphological variability in adolescent Japanese-English interlanguage," Lancaster University 
Postgraduate Conference in Linguistics and Language Teaching, vol. 6, pp. 25-54, 2012.

[15] O. V. Laleko, The Syntax-Pragmatics Interface in Language Loss: Covert Restructuring of Aspect in Heritage Russian, University of Minnesota, Minneapolis, Minnesota, 2010.

[16] H. Ahn and J. Herschensohn, "Anglophone acquisition of case particles in L2 Korean," in Proceedings of the 12th Generative Approaches to Second Language Acquisition Conference (GASLA) 2013), Cascadilla Proceedings Project, Somerville, MA, USA, pp. 1-10, January 2013.

[17] A. Albirini and E. Benmamoun, "Concatenative and nonconcatenative plural formation in L1, L2, and heritage speakers of Arabic," The Modern Language Journal, vol. 98, no. 3, pp. 854-871, 2014.

[18] D. M. Bates, lme4: Mixed-Effects Modeling with R, Springer, Berlin, Germany, 2010.

[19] A. Albirini, E. Benmamoun, and B. Chakrani, "Gender and number agreement in the oral production of Arabic Heritage speakers," Bilingualism: Language and Cognition, vol. 16, no. 1, pp. 1-18, 2012.

[20] F. A. Alkohlani, "The problematic issue of grammatical gender in Arabic as a foreign language," Journal of Language and Cultural Education, vol. 4, no. 1, pp. 17-28, 2016.

[21] I. Bartning, "Gender agreement in L2 French: pre-advanced vs advanced learners," Studia Linguistica, vol. 54, no. 2, pp. 225-237, 2000.

[22] F. Franceschina, "Morphological or syntactic deficits in nearnative speakers? an assessment of some current proposals," Second Language Research, vol. 17, no. 3, pp. 213-247, 2001.

[23] L. White, E. Valenzuela, M. Kozlowska-Macgregor, and Y. K. Leung, "Gender and number agreement in nonnative Spanish," Applied Psycholinguistics, vol. 25, no. 1, pp. 105-133, 2004.

[24] C. McCarthy, Morphological Variability in Second Language Spanish, McGill University, Montreal, Canada, 2007.

[25] S. Montrul, R. S. Foote, and P. Perpiñán, "Gender agreement in adult second language learners and Spanish heritage speakers: the effects of age and context of acquisition," Language Learning, vol. 58, no. 3, pp. 503-553, 2008.

[26] J. Bruhn de Garavito and L. White, "L2 acquisition of Spanish DPs: the status of grammatical features," The Acquisition of Spanish Morphosyntax: The L, vol. 1, pp. 151-176, 2002. 